\title{
Employee motivation and job performance: a study of basic school teachers in Ghana
}

\author{
Joseph Ato Forson ${ }^{1 *} \mathbb{0}$, Eric Ofosu-Dwamena ${ }^{2}$, Rosemary Afrakomah Opoku ${ }^{3}$ and \\ Samuel Evergreen Adjavon ${ }^{4}$ (D)
}

\begin{abstract}
Motivation as a meaningful construct is a desire to satisfy a certain want and is a central pillar at the workplace. Thus, motivating employees adequately is a challenge as it has what it takes to define employee satisfaction at the workplace. In this study, we examine the relationship between job motivation factors and performance among teachers of basic schools in Ghana. The study employs a quantitative approach on a sample of 254 teachers from a population of 678 in the Effutu Municipality of Ghana, of which 159 questionnaires were duly answered and returned (representing $62.6 \%$ return rate). Using multiple regression and ANOVA, the study finds compensation package, job design and environment and performance management system as significant factors in determining teacher's motivation in the municipality. Thus, these motivation factors were significant predictors on performance when regressed at a decomposed and aggregated levels. These findings support the self-determination theory, more specifically on the explanations advanced under the controlled and autonomous motivation factors. Significant differences were also observed in teachers' performance among one of the age cohorts. The study urges the municipal directorate of education to make more room for young teacher trainees and interns who are at the formative stage of their careers to be engaged to augment the experienced staff strength. More should be done to make the profession attain some level of autonomy in the discharge of duty to breed the next genre of innovative educators in the municipality.
\end{abstract}

Keywords: Motivation, Performance, Compensation package, Performance management systems, Single spine salary structure (SSSS)

JEL Classification: D63, E25, E52, 120, 122

\section{Introduction}

Motivation as a meaningful construct is a central pillar at the workplace. Thus, motivating employees adequately is a challenge as it has what it takes to define employee satisfaction at the workplace. Quite a number of studies have been devoted to the link between motivation and its constituent factors and employee performance in different organizations $[7,46]$. Our study draws inspiration from the self-determination theory (SDT) advanced by Deci et al. [14] as a framework that can be applied to

\footnotetext{
*Correspondence: datoeagle@yahoo.com

${ }^{1}$ Department of Applied Finance and Policy Management, University

of Education, Winneba, P.O. Box 25, Winneba, Ghana

Full list of author information is available at the end of the article
}

teachers motivation and performance in basic schools in Ghana. It is worth noting that SDT differentiates between controlled motivation and autonomous motivation. The latter is evident when individuals are faced with pressure and control. The former on the other hand emphasizes on the volitional nature of the behavior of individuals. The SDT provides evidence that suggests that motivation fuels performance $[14,57]$.

In Ghana, the subject of motivation has always been at the apex of national agenda and is evident in the number of strike actions in the public service. In the early part of the 2000s, teachers were part of the public servants whose agitation for improved condition of service did not go unnoticed. Forson and Opoku [16] had stated that teachers' emolument accounted for less than $35 \%$ of the 
public service wage bill although teachers were perceived to be in the majority in terms of numbers. This phenomenon did spark a wave of attrition of trained teachers to other sectors of the Ghanaian economy. The teaching profession as a matter of fact became a launched pad for the youth. It should be said that the nature of the school setting is basically a function of internal management and leadership. The head teacher or director of education as the Chief Executive needs to appreciate and recognize that results can be obtained through people. In today's world, organizations are concerned with what should be done to achieve sustained high level of performance through people who are innovative thinkers $[4,17,41]$. These include paying more attention to how individuals can best be motivated and provision of an atmosphere that helps individuals to deliver on their mandates in accordance with the expectations of management [25]. This means that an educational manager or an individual engaged as a teacher cannot do this job without knowing what motivates people. The building of motivating factors into organizational roles and the entire process of leading people should be contingent on knowledge of motivation. Koontz and Weinrich [25] agree that the educational managers' job is not to manipulate people but rather to recognize what motivates people.

A national debate ensued on the significant role played by teachers in nation building and the need to address the shortfall in the condition of service of teachers to motivate them to perform. Wider consultative meetings were held with stakeholders in the teaching fraternity and the outcome and the panacea was the introduction of a uniform pay structure based on qualification. The legislative arm of government passed Act 737 in 2007 that saw the birth of the Fair Wages Salary Commission (FWSC). The mandate of the commission was to ensure a fair and systematic implementation of government pay policy [18]. Although this has stabilized the teaching profession in terms of the level of attrition, concerns on how this inducement translate into teacher's performance seem to dominate national discourse especially in the face of fallen standard of education in Ghana. Such concerns have raised questions such as the following: (1) Does pay rise correlate with performance? (2) Are there other factors that ought to be considered in the nexus between motivation and performance? (3) Are there any significant differences in the level of performance among various age cohorts (4) Do educational background motivate teachers to perform better? These and other questions are addressed in this study.

The objective of this paper is to examine the link between job motivation factors and performance among basic school teachers in Ghana. This is against the backdrop that teachers have for some time now complained about condition of service and with the passage of FWSC bill, one would have thought that would have impacted on performance of teachers as it has been proven that motivation leads to satisfaction and ultimately to high performance. The standard of education continues to be a major concern in the educational setup of Ghana.

We organize the paper as follows: section one is the introduction that sets the tone for the paper. The problem is defined in this section, and the necessary questions that warrant redress are asked. We continue with a brief literature review on the concept of motivation, leading to the development of a conceptual framework and hypothesis based on the self-determination theory (SDT). Section two focuses on the method deployed, with emphasis on the aim, design and setting of the study. The theoretical equation for the multiple regression is brought to the fore here. Section three is the results and discussion, and section four concludes with policy implications.

\section{The concept of motivation and self-determination theory (SDT)}

Maslow [33] is credited for being part of the early contributors of human motivation concept. Maslow classifies human needs that motivate them into two: (1) homeostasis and (2) finding that appetites (preferential choices among foods). The former refers to the body's automatic efforts to maintain a constant, normal state of the blood stream. The latter concept, on the other hand, is of the view that if the body lacks some chemical, the individual will tend (in an imperfect way) to develop a specific appetite or partial hunger for that missing food element. Thus, Maslow was of the view that any of the physiological needs and the consummatory behavior involved with them serve as channels for all sorts of other needs. Relating this assertion to teachers and the need for a salary pay rise, it should be pointed out that a person who thinks he is hungry may actually be seeking more for comfort, or dependence and managers in the educational sector ought to know this. Contemporary researches have expanded on the theory of motivation as advanced by Maslow [33, 34]. For an organization to thrive and be efficient, certain conditions ought to be available in order for managers to get the best out of its human resources (workers/employees). Employees of an organization are the greatest asset in a dynamic and competitive environment [49]. In the words of Martin [32], if an organization wants to be effective and aims to sustain the success for a longer period of time, it is important for it to have a motivated workforce made up of employees ready to learn. The last three decades have witnessed an avalanche of studies that emphasizes on the point that employee motivation is essential for the success of a business [2]. 
In exploring further on this connection, Mifflin [35] delved into the fundamental meaning of the word "motivation" and pointed out that it is a Latin word which means to move. Therefore, it is near impossible to move peoples' behavior in an organization unless such move is triggered by certain incentives. Robins and Coulter [49] explained the term motivation as the desire and willingness to exert high level of inspiration to reach organizational goals, conditioned by the efforts ability to satisfy some individual need. In this study, we define motivation simply as the act of moving people triggered by the provision of some incentives to achieve a desired goal.

In the words of Deci and Ryan [13], the SDT focuses on human beings inherent desire to bring change and progress as they advance to their fullest potential. Several studies have applied the SDT in various research areas that includes education, medicine and other organizational context. The SDT is of the view that individuals are by nature active entities who will do everything possible to be integrated into the wider social environment in an attempt to be responsive to the behavior consistent with existing self. The theory according to Trépanier et al. [57] defines social context as the workplace which facilitate or frustrate ones striving toward self-determination.

The SDT theory has two major forms of motivation which may be differentiated on the basis of its nature and quality according to Howard et al. [22]. When employees engage in interesting activities or in pursuance of their needs, such a form of motivation is ascribed as autonomous motivation. Such a form of motivation facilitates employees' vitality and energy including satisfaction and well-being [14]. When employees engage in activities out of pressure as a result of external factors such as attaining rewards including threat of being punished, or even endogenous sources of such pressure as maintaining selfesteem, want of approval, image management or avoiding guilt, such a form of motivation can be ascribed as controlled motivation. Gillet et al. [20] explain that people with controlled motivational behavior do so out of reason as long as these contingencies exist and thus it predicts maladaptive work outcomes (e.g., exhaustion of personal energy) and turnover intentions.

\section{SDT and job performance}

According to Motowildo et al. [38], job performance is a construct that elicits behavior related to achievement with evaluative components. Most studies on this relationship have emphasized on the role of autonomous and intrinsic motivation on performance with the argument that individuals autonomously motivated have certain inherent values and behaviors and thus give off optimal performance. The theory of self-determination explains that autonomous motivation should be the necessary ingredient for better performance. That is, when individuals are better informed about the purpose of their job and have a sense of ownership and the degree of freedom to operate (autonomy), the possibility of they performing better at work may be high. The source of such motivation according to Deci et al. [14] may be from one's interest and values. It is purpose-driven, amplifies energy, enjoyable and provides enough rationalization for tasks to be accomplished effectively. Moreover, the intrinsic component of autonomous motivation has been linked with job performance in related literature and types of performance [7].

Empirically, there are evidence to suggest that autonomous motivation is linked with performance. Evidence pertaining to controlled motivation is less dispositive. Proponents of the SDT have argued that controlled motivation (e.g., performance management systems) could reduce employee functioning because action derived from personal values and interest may be disconnected, therefore leading to negative effects on performance [48]. Counter argument posits that controlled motivation may foster employee willingness to complete tasks in an attempt to avoid guilt or punishment or to earn external reward which may come in the form of compensation package [27]. In this study, we focus on both the controlled and autonomous motivational factors. More specifically, we focus on Herzberg et al. [21] motivators validated by Harvard Business Review in 2003 which were made up of two motivators: (1) intrinsic factors such as achievement, recognition for achievement, the work itself, growth, responsibility and advancement, and (2) extrinsic factors such as supervision, working conditions, payment, interpersonal relationship, appreciation and company policy. Therefore, the bundle of motivators used in this study are similar to the aforementioned ones and may include performance management systems, external rewards that come in the form of compensation packages, job environment and training and development [30]. We explain these constructs further with the empirical evidence leading to the development of the conceptual framework.

\section{Compensation package}

Rasheed et al. [44] posit that package of compensation offered to teachers in institutions of higher learning has to be made based on several factors that may include the experience that underpins the abilities of the teacher, qualifications and perhaps market rates. This is supported by Bohlander et al. [6] who argued that teachers compensation ought to be the most central concern for managers and administrators of schools in stimulating them. Most of these research studies are premised on the fact that compensation should be designed to meet 
the needs of teachers and has be fashioned in the form of tangible rewards. In corroborating this assertion, Marlow et al. [31] observed that low condition of service defined by salary creates stress among teachers in schools. Thus, teachers' condition of service should be market competitive in order to get higher motivation and to maintain them. Other studies have found that salary levels have been the main challenge for education managers and are the reason for the high attrition and that education planners and managers should pay attention to the design of compensation packages.

\section{Job design and working environment}

The needs of teachers on the job ought to be planned properly. The workload on teachers should not be such that it will de-motivate [44], p. 103. Teachers at all levels should have a learning environment, and educational administrators should make a point to treat existing human resource (teachers) with maximum respect devoid of any discrimination.

Nowadays, job design is the central focus of managers and human resource researchers. Thus, a well-designed job has what it takes in getting interest of employees. On the contrary, poorly designed job breeds boredom among employees. Davidson [12] makes an important observation and remarked in his research that when teachers are overloaded and burdened with so many nonteaching activities, it portends as a hindrance in the job design. Other scholars such as Clarke and Keating [9] have argued that the working environment of an educational institution affects teachers' motivation. Clarke and Keating [9] found students to be the main reason why teachers are motivated in schools. His emphasis was on talented and hardworking students who boost the morale of teachers. Students who do not produce the desired results, on the other hand, de-motivate teachers. Moreover, class size is another important consideration in motivating teachers. Other variants of the job design and environment are captured in Ofoegbu [39] research in which he argued that institutions provide support in the form of resources to the teachers in the form of computers with Internet connections. Moreover, other factors such as the provision of e-libraries and research equipment, and other logistics for students may also serve as an effective motivator for teachers.

\section{Performance management system}

Management of teachers and educational administrators in all levels of education should focus on implementing basic performance management systems to continually appraise teachers' accomplishments. For instance, the use of a so-called 360-degree feedback system is important where students' feedback is attended to with the attention it deserves.
Stafyarakis [53] corroborated this and asserted that 'Annual Confidential Reports' have become obsolete. Yet there has been an emergence of a scientific approach on the field of performance management as time goes on. In discussing this further, Milliman [37] is of the view that although there are many practices available in this field, but a performance management system based on 360-degree feedback approach is the most effective.

Contrary to the norm that teachers are most motivated by the intrinsic factors and least motivated by the monetary aspects of teaching, Rao [43] demonstrates that poor appraisal systems, lack of recognition and lack of respect from the head and other co-workers are some common reasons of distress and de-motivation among teachers in educational institutions. The lack of recognition from supervisors is one of the many reasons why teachers would want to leave the teaching profession Stafyarakis [53].

Moreover, Rasheed et al. [45] points out that teachers are much concerned about students' feedback; hence, feedback from the students should be given a proper weightage and in appraising and managing teachers' performance in the institutions of higher education. Jordan [23] stressed that the feedback of students is a major issue of that motivates teachers and therefore teachers should be given feedback from their students in scientific manners.

\section{Training and development}

It is of significance that educational administrators focus on training activities as an essential means of both motivating employees and sustaining the survival of that organization according to Photanan [42] and Bohlander et al. [6]. Leslie [28] identified professional growth as basic motivator for teachers. He stressed that the professional learning platform available to a teacher is the basic path of his/her career development [29].

\section{Conceptual framework and hypothesis development}

In this section, the study harmonizes the components of the SDT theory into a conceptual framework on motivation and performance connection. The framework developed in this research may be useful as a guide by academicians and practitioners in understanding the mechanisms through which motivational factors affect job performance among teachers in the Effutu Municipality of Ghana. On elucidating on what a framework is, Chinn and Kramer [8] explained that a framework can be seen as a complex mental formulation of experience. Further clarification was given to distinguish conceptual framework from a theoretical framework. They assert that while theoretical framework is the theory on which the study is based, the 
conceptual framework deals with the operationalization of the theory. Put in another way, it represents the position of the researcher on the problem at hand and at the same time gives direction to the study. It may be entirely new, or an adoption of, or adaptation of, a model used in previous research with modification to fit the context of the inquiry [8].

The framework developed in this research has three components: the first component looks at the factors necessary to induce motivation among teachers. The second component focuses on motivation as a concept. The last component which is on job performance looks at the link between the aggregate motivational factors and performance. The extant literature survey on motivational factors and performance provides all the necessary ingredients for the construction of the framework. First, the extant literature shows that motivation as a concept is simply the act of moving people triggered by the provision of some incentives to achieve a desired goal. The triggers of motivation may include such factors such as compensation packages, job design and working environment, performance management system and training and development which are controlled and autonomous factors as crucial elements for motivation.

The second component of the framework is the aggregate motivation, which is the interaction of the controlled and autonomous factors of motivation. Motivation according to Reeve (2001) refers to the excitement level, the determination and the way a person works hard at his work setting. Ricks et al. [47] explicating on the thesis of motivation was of the view that motivation is an internal aspiration of a man that compels him to reach an objective or the goal set for him.

The third component of the framework is performance. According to Culture IQ [11] and Motowildo et al. [38], job performance is the assessment of whether an employee has done their job well. It is an individual evaluation (one measured based on a single person's effort). In the words of Viswesvaran and Ones [58], p. 216, the term job performance is used in reference to actions that are scalable, behavior and outcomes that employees engage in or bring about that are linked with and contribute to the goals of an organization. It is linked to both employee- and organizational-level outcomes. A distinctive feature of the framework developed in this research is that it shows the interaction between autonomous and controlled factors and motivation and how it affects the performance of teachers in Fig. 1.

It can be visibly seen from the framework that teachers motivation may be defined by both controlled and intrinsic motivational factors that may include those that fall under compensation packages, working environment, performance management system and training and development of teachers [44]. Yet the performance of teachers in itself motivates management and policy makers to institute compensation packages, improved psychological aura through enhanced working environment and job design and implementing appropriate performance management policy for a continued performance enhancement. It should also be emphasized here that these job satisfaction factors may pass as job motivational factors and theorize that a highly motivated teacher may be related to the level of satisfaction.

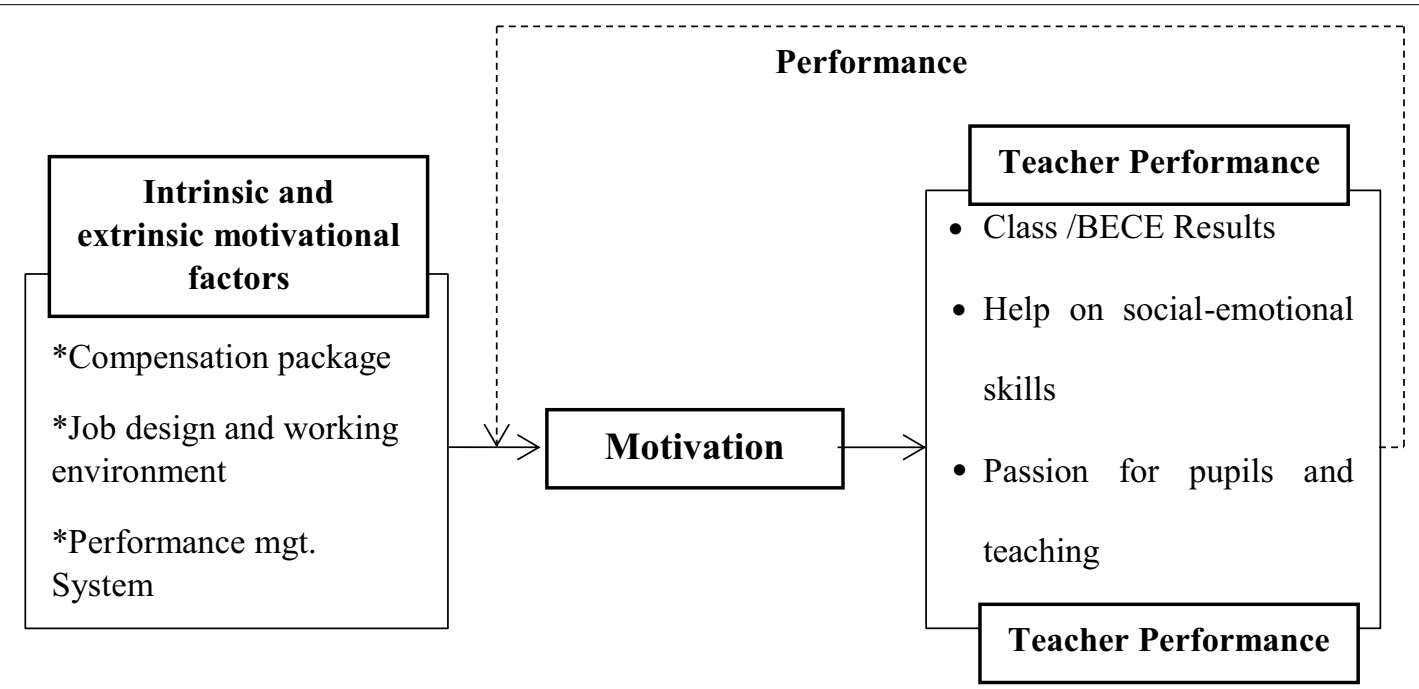

Fig. 1 A Conceptual model of the relationship between Motivation and Teachers' Performance. Source: Created by the authors 
Scholars such as Thus Milda et al. [36] and Spector [52] collectively share the opinion that teachers differ from typical employees in various ways. Therefore, instruments that usually measure such job satisfaction and motivation dimensions as appreciation, communication, coworkers, fringe benefits, job conditions, nature of work, organization itself, organizations' policies and procedures, pay, personal growth, promotion opportunities, recognition, security, supervision may not always match with teachers' motivation aspects on the teaching field. However, some of these factors according to some researchers can be used in understanding motivation and performance among teachers. The consensus on these dimensions is especially on supervision, work itself, promotion and recognition being important dimensions of teachers' motivation at work $[50,51,56]$. In addition, several researchers have used the same measurement or dimension but with different wording (synonym). For instance, Kreitner and Kinici [26] define job satisfaction with the synonym "motivation" which they argue contains "those psychological processes that cause the arousal, direction and persistence of voluntary actions that are goal directed" Motivation depends on certain intrinsic, as well as extrinsic factors which in collaboration results in fully committed employees. Based on this relationship, we hypothesize that:

Hypothesis 1 Teachers' compensation package, job environment and design, performance management systems, training and development significantly affect teachers' motivation.

In a similar manner, Board [5] asserted that tangible incentives are effective in increasing performance for task not done before, to encourage "thinking smarter" and to support both quality and quantity to achieve goals. Incentives, rewards and recognitions are the prime factors that impact on employee motivation. Aarabi et al. [1] confirmed this assertion by making use of factors such as payment, job security, promotion, freedom, friendly environment, and training and employee job performance to measure the term organizational motivation with positive relationship found on these factors. On rewards (which comes in various forms, e.g., income/pay, bonus, fringe benefits among others) and recognition/appreciation, according to other researchers keep high spirit among employees which boost employee's morale which may have a direct impact on performance and output. The study hypothesizes that:

Hypothesis 2 Teacher's motivation positively affects their performance.

\section{Methods}

\section{The aim, design and setting of the study}

The paper aims to examine the link between motivation factors and performance among basic school teachers in Ghana. Data for this study were collected from primary. Primary data were sourced from the field of study through questionnaire administration. The researchers sought for permission from the municipal directorate of education to engage with teachers within the municipality. A written permission was granted, and questionnaires were administered to all basic schools' teachers in the municipality.

At the preparatory stage, the questionnaires designed were tested to make sure participants understood the demands of the questions in the questionnaires. Informal interviews method has been adopted to make sure that additional information that could not have been gathered through the use of questionnaires was captured. The formal interviews using questionnaires ensured that we stayed focused on the background objective that formed the basis of the study.

\section{Sampling technique and data analysis}

On the determination of the sample size, different authors have differing views, but in most cases, the recommendation is that it should be large. Stevens [54] recommends at least 15 participants per predictor for reliable equation in the case of factor analysis. Tabachnick and Fidel [55] provides a formula for calculating sample size requirements, taking into consideration the number of independent variables that one wish to use: $N>50+8 m$ (where $m=$ number of independent variables). In line with these and other requirements like Yamane [60], the exact sample size will be determined and questionnaires distributed accordingly to the selected public and private schools in the Effutu Municipality.

The human resource unit of the educational directorate of education in the municipality has indicated that there are over 678 teachers teaching at various levels in the municipality [15]. Thus, the 678 teachers become the population in the municipality. Using Yamane [60] and validating with other sampling size technique, a sample size of 254 has been adopted with a 0.5 level of precision. Thus, 254 questionnaires were distributed among the various schools, but 159 were filled and returned (representing 62.6\% return rate).

Quantitative data are analyzed by means of a software called Statistical Package for Social Sciences (SPSS version 20). This is necessitated by the fact that the analyzed quantitative data ought to be presented by graphs to give quick visual impression of what it entails.

The scale measurement of the questionnaires included nominal scale, ordinal and intervals. 
Questionnaires used were segmented to capture the demographic characteristics of the respondents and the constructs that feeds into the multi-level latent variables using a five-point Likert scale (see $[19,24]$ ). A verification was done to assess the suitability of the data for factor analysis with the expectation that Kaiser-Meyer-Olkin Measure of Sampling Adequacy (i.e., KMo $\geq 0.6$ ) and Bartlett's Test of Sphericity value are significant $(p=0.05)$, which was the case for our sample data. In measuring some of the latent variables, the study developed a 9-scale item on compensation package with the following loadings (e.g., how high is your qualification and pay $(\alpha=0.72)$, "is your experience linked to your current pay?" $(\alpha=0.80)$, "are you satisfied with the market premium" $(\alpha=0.75)$ etc.). All items were rated on a five-point Likert scale ranging from $1=$ "not important" to $5=$ "very important." A confirmatory factor analysis (CFA) indicates that the hypothesized correlated 3-factor structure fits well with the responds of the participants $\left(\chi^{2} / d f=2.01, \mathrm{RMR}=0.05, \mathrm{RMSEA}=0.06, \mathrm{TLC}=0.94\right.$, $\mathrm{CFI}=0.94)$.

Job design and working environment was measured by a 7-item scale based on questions such as "how do you perceive your workload" $(\alpha=0.88)$, "does your work type offer learning environment?" $(\alpha=0.83)$, "Are you inspired by your working environment?" ( $\alpha=0.87)$, "Talented student boost morale" $(\alpha=0.84)$ etc. Similarly, all items were rated on a five-point Likert scale ranging from $1=$ "not important" to $5=$ "very important." A confirmatory factor analysis reveals that the hypothesized one-factor structure fits well with the data $\left(\chi^{2} / d f=3.06, \mathrm{RMR}=0.05, \mathrm{RMSEA}=0.06, \mathrm{TLC}=0.94\right.$, $\mathrm{CFI}=0.94)$.

Performance management system was assessed using a 9-item scale based on these inferences (e.g., "number of times supervisor visits" $(\alpha=0.69)$, "how often are you visited by the municipal director of education" ( $\alpha=0.78)$, "work recognition" ( $\alpha=0.72$ ), etc.). All constructs were rated as $1=$ "not important" to $5=$ "very important." A confirmatory factor analysis reveals that the hypothesized two-factor structure was in line with the data $\left(\chi^{2} / d f=2.86, \mathrm{RMR}=0.05, \mathrm{RMSEA}=0.06, \mathrm{TLC}=0.94\right.$, CFI $=0.94)$.

The last but not the least concept explored was job performance. It was assessed on a 12-item scale based on the inferences such as (e.g., "are pupils treated with respect?" ( $\alpha=0.77)$, "do you help pupils work on their social-emotional skills?" $(\alpha=0.69)$, "are you fair and consistent with pupils" ( $\alpha=0.87)$, etc.). All items were rated on a five-point Likert scale ranging from $1=$ "not important" to $5=$ "very important." A confirmatory factor analysis reveals that the hypothesized two-factor structure was in line with the data $\left(\chi^{2} / d f=2.06, \mathrm{RMR}=0.05\right.$, RMSEA $=0.06, \mathrm{TLC}=0.94$, $\mathrm{CFI}=0.93)$. The study proceeds to make use of the proposed measurement models to assess the relationship outlined in the conceptual model in Fig. 1.

\section{Hypothesized theoretical equation}

Based on the conceptual model in Fig. 1, the study makes a number of hypothesis on the relation between motivational factors and motivation itself and subsequently the link between motivation and performance. Consequently, the study model leads to two structural equations as presented below:

$$
\begin{aligned}
& Y_{\mathrm{JM}}=\alpha+\beta_{1} \mathrm{CP}+\beta_{2} \mathrm{JDWE}+\beta_{3} \mathrm{PMS}+\beta_{4} \mathrm{TD}+\varepsilon_{1} \\
& Y_{\mathrm{JP}}=\alpha+\beta_{1} \mathrm{JM}+\varepsilon_{2}
\end{aligned}
$$

where $\mathrm{JM}=$ job motivation, $\mathrm{CP}=$ compensation package, JDWE $=$ job design and working environment, $\mathrm{PMS}=$ performance management system, $\mathrm{TD}=$ training and development, $\mathrm{JP}=$ job performance.

\section{Results and discussion}

The study begins with a frequency distribution and descriptive statistics to capture the responses of teachers regarding the itemized construct identified in the conceptual model. Beginning with these two is borne out of the fact that the data category used in the study included categorical, ordinal and nominal variables which may be difficult to have a summary descriptive statistic.

With the understanding that every statistical approach is guided by certain principles or in most cases what has come to be known as assumptions, a diagnostic check was undertaken. Multicollinearity and singularity, for instance, look at the relationship among the independent variables. Thus, multicollinearity exists when the independent variables are highly correlated $(r=0.5$ and above). The study was particular about these assumptions because multiple regression abhors them (singularity and multicollinearity). Issues concerning outliers (i.e., very high and low scores) was dealt with given the fact that multiple regression is sensitive to them. On normality, the results of the Kolmogorov-Smirnov statics were used to assess the distribution of scores. The test result was insignificant (i.e., sig. value of more than 0.05 ), which pointed to normality. Having done these, the study was sure there were no errors in the data and that the descriptive phase of the data used can begin.

Consistent with the general distribution of gender in the demographic characteristics of Ghana, about 63 of the teachers were female (39.6\%) with $59.1 \%$ made up of male and $1.3 \%$ being transgender. The transgender 
teachers were foreign teachers who were here on an exchange program. Most of the teachers in the sample taught at the primary level (46.5\%), followed by junior high level (43.4\%) and kindergarten (8.8\%), respectively. About $34.6 \%$ of the respondent responded they have taught between 6 and 10 years and 22.0\% had spent between 11 and 20 years teaching. In terms of educational background, about $50.3 \%$ of the respondent have had first degree, with the remaining $49.7 \%$ being holders of teachers Cert. A or Diploma from the training colleges, and master's degree of the returned samples. The average number of years participants have taught was observed to be 2.34 years with a corresponding standard deviation of 1.010. We present the demographic characteristics of our participants in Table 1.

As shown in Table 2, the compensation package scale has good internal consistency, with a Cronbach alpha coefficient reported to be around 0.725 . According to Pallant [40], Cronbach alpha values above 0.7 are considered acceptable; however, values above 0.8 are preferable. Therefore, the threshold value of 0.725 means our scale is internally consistent and acceptable. Similarly, the job design and working environment scale recorded a Cronbach alpha coefficient of 0.793 .

Performance management on the other hand had a Cronbach alpha coefficient of 0.70 , yet training and development recorded a lower Cronbach alpha of 0.53 ,

Table 1 Demographic characteristics of the teacher participants (total=159). Source: Authors' own construct from Field DataQuestionnaire (2019)

\begin{tabular}{|c|c|c|c|}
\hline Variable & Categories & Frequency & Percentage \\
\hline \multirow[t]{3}{*}{ Gender of teachers } & Male & 96 & 59.1 \\
\hline & Female & 63 & 39.6 \\
\hline & Transgender & 2 & 1.3 \\
\hline \multirow[t]{5}{*}{ Age of teachers } & $18-25$ & 11 & 6.90 \\
\hline & $26-35$ & 43 & 27.0 \\
\hline & $36-45$ & 54 & 33.9 \\
\hline & $46-55$ & 35 & 22.1 \\
\hline & 56 and above & 16 & 10.1 \\
\hline \multirow[t]{3}{*}{ Teachers'academic qualification } & PGDED & 67 & 42.2 \\
\hline & Bachelor's degree & 80 & 50.3 \\
\hline & Master's degree & 12 & 7.50 \\
\hline \multirow[t]{6}{*}{ Rank of teachers } & Senior Sup. II & 42 & 26.4 \\
\hline & Senior Sup. I & 10 & 6.30 \\
\hline & Prin. Superintendent & 92 & 57.8 \\
\hline & Assist. Direct II & 13 & 8.20 \\
\hline & Assist. Direct I & 2 & 1.30 \\
\hline & Deputy Direct I & 0 & 0.00 \\
\hline \multirow[t]{5}{*}{ Years teaching experience } & Less than 2 years & 21 & 13.2 \\
\hline & $2-5$ years & 25 & 15.7 \\
\hline & $6-10$ years & 55 & 34.6 \\
\hline & $11-15$ years & 35 & 22.0 \\
\hline & Over 15 years & 23 & 14.5 \\
\hline
\end{tabular}

Table 2 Descriptive statistics, correlation matrix, reliability and validity test $(N=159)$

\begin{tabular}{llllllll}
\hline Variables & Mean & SD & $\mathbf{1}$ & $\mathbf{2}$ & $\mathbf{3}$ & $\begin{array}{c}\text { Cronbach's } \\
\text { alpha }\end{array}$ \\
\hline Job performance & 56.03 & 4.03 & 1 & & & 0.83 \\
Performance Mgt. System & 18.64 & 1.46 & $0.48^{* *}$ & 1 & $0.43^{* *}$ & 1 & 0.70 \\
Job design and Env & 27.37 & 3.03 & $0.32^{* *}$ & $0.38^{* *}$ & $0.42^{* *}$ & 1 \\
Compensation Package & 40.3 & 4.10 & $0.25^{* *}$ & & 0.79 \\
\hline
\end{tabular}

${ }^{* * *} p<0.01{ }^{* *} p<0.05 ;{ }^{*} p<0.10$ 
which meant it lacked internal consistency. The study had to drop training and development as factor for job motivation and proceed with the others. Job performance, however conspicuously recorded a Cronbach alpha of 0.83 . In terms of the output from the correlation matrix, it can be visibly seen that the scales computed were not highly correlated and fallen below the threshold of 0.8 as recommended (see [40], p. 56). Both the assumption of singularity and multicollinearity by extension have not been violated (see Durbin Watson results) and thus the study can proceed to run the regression as per the set objectives and the conceptual model.

We go further to examine the causal effect of the factors identified as triggers of motivation on teachers' level of motivation using ordinary least square method with multiple regression as the exact approach. Having gained credence from the test of reliability and validity, examining the causal effect becomes imperative. Using the baseline model in Eq. (1), the study concurrently runs the regression with the output shown in Tables 2, 3 and 4.

In model one, the study regresses compensation package with the dependent variable without controlling for other related factors. By implication what the results in model (1) seeks to explain is that, as the value of compensation package for teachers increases by 73 percentage points in the municipality, the mean of job motivation increases by that same margin. The high compensation is evidenced by government of Ghana reform in salary

Table 3 The causal effect of intrinsic and extrinsic factors on teachers' motivation

\begin{tabular}{llll}
\hline Variables & Model (1) & Model (2) & Model (3) \\
\hline $\begin{array}{l}\text { Job motivation } \\
\text { Specifications }\end{array}$ & & & \\
Constant & $88.72^{* * *}$ & $62.68^{* * *}$ & $28.4^{* * *}$ \\
& $(5.58)$ & $(4.95)$ & $(4.06)$ \\
CP & $0.73^{* * *}$ & $0.53^{* * *}$ & $0.42^{* * *}$ \\
& $(0.14)$ & $(0.12)$ & $(0.08)$ \\
JDWE & & $0.49^{* * *}$ & $0.34^{* * *}$ \\
& & $(0.16)$ & $(0.11)$ \\
PMS & & & $0.45^{* * *}$ \\
& & & $0.22)$ \\
Observation & 159 & 159 & 159 \\
R $^{2}$ & 0.529 & 0.73 & 0.882 \\
Adj. R & & 0.72 & 0.880 \\
VIF & 0.525 & 0.83 & 0.787 \\
Tolerance & 1.00 & 1.20 & 1.28 \\
Durbin Watson & 1.00 & 1.90 & 2.10 \\
\hline
\end{tabular}

Robust standard errors in parentheses

Dependent variable: Job motivation

$\wedge\left\{{ }^{*}\right\} p<0.10, \wedge\{* *\} p<0.05, \wedge\{* * *\} p<0.01$
Table 4 Teachers' job motivation and performance

\begin{tabular}{|c|c|c|c|c|c|}
\hline Variables & Model (1) & Model (2) & Model (3) & Model (4) & Model (5) \\
\hline \multicolumn{6}{|c|}{ Teachers' performance } \\
\hline \multicolumn{6}{|c|}{ Specifications } \\
\hline \multirow[t]{2}{*}{ Constant } & $31.92^{* * *}$ & $46.24^{* * *}$ & $44.47^{* * *}$ & $33.99 * * *$ & $30.50^{* * *}$ \\
\hline & $(3.79)$ & $(3.14)$ & $(2.89)$ & $(3.056)$ & $(3.680)$ \\
\hline \multirow[t]{2}{*}{$J M$} & $0.463^{* * *}$ & & & & \\
\hline & $(0.04)$ & & & & \\
\hline \multirow[t]{2}{*}{$C P$} & & $0.253^{* * *}$ & & & $0.039^{* * *}$ \\
\hline & & $(0.08)$ & & & $(0.08)$ \\
\hline \multirow[t]{2}{*}{ JDWE } & & & $0.32^{* * *}$ & & $0.103^{* * *}$ \\
\hline & & & $(0.104)$ & & $(0.108)$ \\
\hline \multirow[t]{2}{*}{ PMS } & & & & $0.510^{* * *}$ & $0.443^{* * *}$ \\
\hline & & & & $(0.08)$ & $(0.085)$ \\
\hline $\begin{array}{l}\text { Observa- } \\
\text { tion }\end{array}$ & 159 & 159 & 159 & 159 & 159 \\
\hline$R^{2}$ & 0.214 & 0.064 & 0.100 & 0.260 & 0.275 \\
\hline Adj. $R^{2}$ & 0.209 & 0.058 & 0.094 & 0.256 & 0.261 \\
\hline VIF & 1.00 & 1.00 & 1.00 & 1.00 & 1.2 \\
\hline Tolerance & 1.00 & 1.00 & 1.00 & 1.00 & 0.787 \\
\hline $\begin{array}{l}\text { Durbin } \\
\text { Watson }\end{array}$ & 2.04 & 1.91 & 1.95 & 2.05 & 2.11 \\
\hline
\end{tabular}

Robust standard errors in parentheses

Dependent variable: teachers performance

${ }^{*} p<0.10,{ }^{* *} p<0.05,{ }^{* * *} p<0.01$

structure and bolstered by the effort of the Member of Parliament (MP) through the sharing of teaching and learning materials (TLMs) in the municipality. By this gesture by the MP, teachers feel appreciated and derive high motivation. Moreover, the presence of a university (University of Education, Winneba) has helped to deepen the level of motivation. The model has cross-variable variance of 52 percentage and with close to about 48 percentage unexplained as inferred from the coefficients of both coefficient of determination $\left(R^{2}\right)$ and adjusted coefficient of determination. Generally, the model is jointly significant $(F=170, p<0.01)$ with a corresponding tolerance and variable inflationary factor (VIF) of 1.

In model (2), the study varies the variables used with the inclusion of job design and working environment to examine how well the model can be through it cross-variable variance. Controlling for job design and environment shows a significant drop in the coefficient of compensation package from 0.73 to 0.53 although highly significant. Job design and environment recorded a coefficient of 0.49 which meant this indicator increases teachers' satisfaction and thus motivation by 49 percentage points. In explaining this phenomenon, one would say that jobs that are rich in positive behavioral essentials such as autonomy, task significance and identity and feedback contribute to employees' motivation. Government has since 
the introduction of its flagship program on free senior high education emphasized the significance of education across all the strata. The autonomy of heads of unit was by this directive curtailed. Heads of unit were barred from initiating policies to ease their operations. This finding is supported in the literature $[7,30,46]$ and is aligned with the SDT. For example, head teachers who had levied pupils with printing fees were sanctioned for such initiative. Thus, by this gesture, the autonomy of the profession was in doubt and this explains why the level of motivation when this parameter is mentioned is low. With this addition, model (2) marginally sees an improvement of 0.73 in the cross-variable variance which is a significant. Model (2) was jointly significant $(F=170, p<0.01)$.

All the identified job motivation variables are concurrently used in model (3) to infer whether there was going to be a significant increase in the coefficient of determination and a drop in the residue. As a confirmation to the priori assumption, there was a marginal improvement of the explanatory strength of the model $\left(R^{2}=0.88\right)$. However, the model witnessed significant drop in the coefficients. Thus, compensation package dropped further from 0.53 to 0.42 and job design and environment from 0.49 to 0.34 .

It is important to note that the value of Durbin Watson test results when all the identified factors are brought together in model (3) indicate a no autocorrelation in the model which validates the earlier point of having dealt with critical assumptions that borders on autocorrelation. Moreover, both our VIF and tolerance were within the acceptable level. For instance, models (1)-(3) had a VIF score less than or equal to 1 , which meant there were no issues concerning a possibility of high multicollinearity. For tolerance, there are no clear-cut cut-off point, but there is a suggestion of a tolerance greater than 0.40 according to Allison [3]. Yet Weisburd and Britt [59] are of the view that anything below 0.2 is an indication of serious multicollinearity. Inferring from these, it therefore goes to suggest that the tolerance levels of above 1 meant no multicollinearity.

In examining the relationship between the aggregated motivational factors and performance, the study brings to the fore the following findings as shown in Table 3. The study presents four (4) different models on the relationship between motivation and performance. Model (1) regresses the aggregate motivational factors on job performance, and the findings are quite interesting to note. The job performance indicator is increased by $46 \%$ for every unit increase in motivation. This relationship can further be explained to mean a teacher within the municipality with a sense of satisfaction with his/her teaching job may feel more inclined to be at post no matter what the prevailing circumstances are. The snowball effect of this phenomenon is the reduction in absenteeism with a corresponding curb on teachers' turnover. Although the coefficient of determination which explains the cross-variable variance is by far lower than expected $\left(R^{2}=0.214\right)$, the model is jointly significant $(F=41.44$, $p<0.01)$. The VIF and tolerance levels are within acceptable threshold with a Durbin Watson of 2.04 that signals a no concern of autocorrelation in the model.

Models (2)-(4) regress the decomposed job motivation factors on performance to ascertain their level of significance, and indeed, as theorized, these factors were positively significant except with lower coefficient of determinations $\left(R^{2}\right)$. To explain the relation in model (2), it is important to note that compensation is the output and the benefit that a teacher within the municipality receives in the form of pay, or even any form of exchanges (in kind or in cash) to increase performance. The Member of Parliament for the area as part of effort to ensure teachers are well compensated shared over 700 laptops to teachers within the municipality for effective teaching and learning. This certainly explains why the attrition rate in the municipality is low vis-à-vis high morale of teachers which largely explains the level of motivation and satisfaction.

Model (3) touches on the psychological state the teacher finds him or herself owed to the nature and state of the job. This may include the job environment and the degree of specialization. Yet in model (4), there is an exponential increase in the coefficient of performance management systems as it increases job performance within the municipality by 51 percentage point. It should be noted that performance management sets expectations for teachers' performance and thus motivates them to work harder in ways expected by the municipal directorate of education under GES. The results in model (5) confirm earlier ones, but the inclusion of the other variables as control seems to have increased the coefficients of the various motivational factors. This partly explains the performance of the municipality in the central region in successive BECE.

Further investigation is made to understand which of the age groups is responsible for the ensuing level of performance in the municipality. To do this, the study relies on one-way analysis of variance (ANOVA). Here, the mean scores of more than two groups are compared using a continuous variable as the dependent variable. Having transformed the ordinal variables to continuous, it makes it quite straightforward to do this. Using the categorical independent variable of age which has more than three categories and the job performance variable which we have transformed to be continuous variable, the study undertakes a one-way between groups ANOVA with post hoc tests. Teachers 
were divided into four groups according to their ages (group 1: 20-30 yrs.; group 2: 31-40 yrs.; group 3: 41-50 yrs.; group 4: above 51 yrs.). There was a statistically significant difference at the $p<0.10$ level in job performance scores for the four age groups: $F(4$, $159)=0.042, p=0.10$. Despite reaching statistical significance for one of the groups, the actual difference in mean scores between the groups was quite small. The effect size was calculated using eta squared (eta squared $=179.1 / 8513=0.02$ ) which in Cohen's ([10], pp. 248-7) terms is considered far too small a size. Note should be taking that Cohen categorizes 0.01 as a small effect, 0.06 as a medium effect and 0.14 as a large effect. Post hoc comparisons using the Tukey HSD test indicated that the mean score for group 1 (56.12, $\mathrm{SD}=4.26)$ is significantly different from the other three groups which were insignificant. The result has theoretical soundness. Group 1 was made up of young teachers who had either returned from training colleges after completion or on internship and thus had cause to perform for a possibility of being retained or given a very good report since internship supervision forms part of the trainees' assessment.

\section{Conclusion}

In this study, we examined among a host of autonomous and controlled motivational factors and their relationship to performance among basic schools' teachers in the Effutu Municipality of Ghana. A conceptual model was developed with the necessary hypotheses formulated. Using multiple regression and one-way analysis of variance (ANOVA), the causal effect as shown in the model is tested.

The study finds compensation package, job design and environment and performance management system to be positively significant factors in explaining teacher's motivation in the municipality. These job motivation factors were significant predictors on job performance. The aggregated job motivation indicator when regressed on job performance reveals a positive and significant effect. Based on the results from the ANOVA, the study recommends the municipal directorate of education to make more room for young teacher trainees who are at the formative stage of their career to be engaged to augment the experienced staff strength. More should be done to make the profession attain some level of autonomy in the discharge of duty to breed the next genre of innovative educators in the municipality. A limitation of the study is its inability to treat job motivation as a mediatory variable as captured in the framework. The study recommends future research to explore this connection.

\section{Abbreviations}

ANOVA: Analysis of variance; SDT: Self-determination theory; SSSS: Single spine salary structure; FWSC: Fair wages salary commission; TLM: Teaching and learning materials; MP: Member of parliament; JM: Job motivation; CP: Compensation package; JDWE: Job design and working environment; PMS: Performance management system; TD: Training and development; JP: Job performance; KMO: Kaiser-Meyer-Olkin; CFA: Confirmatory factor analysis; SRMR: Standardized root mean square residual; RMSEA: Root mean square error of approximation; SPSS: Statistical package for social science; VIF: Variable inflationary factor.

\section{Acknowledgements}

The authors would like to acknowledge the support of the Effutu Directorate of Education, particularly the Municipal Director of Education for the support during the data collection stage. We thank all the basic school teachers in the municipality who devoted time to fill and return questionnaires sent to them. We are also grateful to the Directorate for the secondary materials given to the team.

\section{Authors' contributions}

JAF contributed 50\%, EOD contributed 25\%, RAO contributed 20\%, and SEA contributed $5 \%$, respectively. All authors have read and approved the manuscript.

\section{Funding}

Not applicable.

Availability of data and material

Not applicable.

\section{Declarations}

\section{Competing interests}

The authors declare that they have no competing interests.

\section{Author details}

${ }^{1}$ Department of Applied Finance and Policy Management, University of Education, Winneba, P.O. Box 25, Winneba, Ghana. ${ }^{2}$ Department of Educational Foundations, University of Education, Winneba, Winneba, Ghana. ${ }^{3}$ Department of Educational Administration and Management, University of Education, Winneba, Winneba, Ghana. ${ }^{4}$ Department of Applied Finance and Policy Management, University of Education, Winneba, Winneba, Ghana.

Received: 21 February 2021 Accepted: 11 June 2021

Published: 4 September 2021

\section{References}

1. Aarabi MS, Subramaniam IV, Akeel AB (2013) Relationship between motivational factors and job performance of employees in Malaysian Service Industry. Asian Soc Sci 9(9):301-310. https://doi.org/10.5539/ass.v9n9p 301

2. Al-Alawi Al (2005) Motivating factors on information technology employees in Bahrain Hotel Industry.

3. Allison P (1999) Multiple regression: a primer. Pine Forge Press

4. Armstrong M (2003) Handbook of management and leadership: a guide to management for results. Kogan

5. Board LM (2007) Coaching a stockholder on performance improvement option. In: ASTD international conference

6. Bohlander G, Snell S, Sherman A (2001) Managing human resources. South-Western College

7. Cerasoli CP, Nicklin JM, Ford MT (2014) Intrinsic motivation and extrinsic incentives jointly predict performance: a 40-year meta-analysis. Psychol Bull 140(4):980-1008

8. Chinn PL, Kramer MK (1999) Theory and nursing: integrated knowledge development, 5th edn. Mosby Inc

9. Clarke R, Keating WF (1995) A fresh look at teacher job satisfaction (ED 391; 795). 
10. Cohen JW (1988) Statistical power analysis for the behavorial sciences, 2nd edn. Lawrence Erlbaum Associates

11. Culture IQ (2018) Understanding job performance in your company. Job Performance.

12. Davidson E (2005) Understanding and improving quality in Tanzanian primary schooling. University of East Anglia

13. Deci EL, Ryan RM (2000) The 'what' and 'why' of goal pursuits: human needs and the self-determination of behavior. Psychol Inq 11(4):227-268

14. Deci EL, Olafsen AH, Ryan RM (2017) Self-determination theory in work organizations: the state of a science. Annu Rev Organ Psych Organ Behav 4(1):19-43

15. EMA (2019) Effutu Municipal Directorate

16. Forson JA, Opoku RA (2014) Government's restructuring pay policy and job satisfaction: the case of teachers in the Ga West Municipal Assembly of Ghana. Int J Manag Knowl Learn 3(1):79-99. https://doi.org/10.2139/ ssrn.2457629

17. Forson JA, Opoku RA, Appiah MO, Kyeremeh E, Ahmed IA, Addo-quaye R, Peng Z, Acheampong EY, Bekuni B, Bingab B, Bosomtwe E (2020) Innovation, institutions and economic growth in sub-Saharan Africa-an IV estimation of a panel threshold model. J Econ Admin Sci. https://doi.org/ 10.1108/JEAS-11-2019-0127

18. FWSC (2013) Is performance management in Ghana's public service a mirage? The fair wages and salaries commission's role in public service performance management. http://www.fairwages.gov.gh/index.php/ Slideshow-News/is-performance-management-in-ghanas-public-servi ce-a-mirage/The-Fair-Wages-and-Salaries-Commissions-Role-in-PublicService-Performance-Management.html

19. Gall P, Gall D, Borg W (2007) Applying educational research. Pearson Education Inc

20. Gillet N, Vallerand RJ, Lafreniere MAK, Bureau JS (2013) The mediating role of positive and negative affect in the situational motivation-performance relationship. Motiv Emot 37(3):465-479

21. Herzberg F, Mausner B, Synderman B (1959) Motivation to work. Wiley

22. Howard JL, Gagné M, Bureau JS (2017) Testing a continuum structure of self-determined motivation: a meta-analysis. Psychol Bull 143(12):1346-1377

23. Jordan JL (1992) Performance appraisal satisfaction and supervisor's traits. Psychol Rep 66(1):1337-1338

24. Kerlinger FN (1978) Foundation of behavioral research. Holt, Rinehart and Winston, New York

25. Koontz H, Weinrich H (1998) Essentials of management, 5th edn. McGraw-Hill, London

26. Kreitner R, Kinici A (2004) Organizational behavior. McGraw-Hill, Irwin

27. Kuvaas B, Buch R, Weibel A, Dysvik A, Nerstad CGL (2017) Do intrinsic and extrinsic motivation relate differently to employee outcomes? J Econ Psychol 61(1):244-258

28. Leslie K (1989) Administrators must consider and improve teacher satisfaction. NASSP Bull 73(1):19-22

29. Lynn S (2002) The winding path: understanding the career cycle of teachers. Clearing House J Educ Strat Issues Ideas 75(4):179-182

30. Manolopoulos D (2008) An evaluation of employee motivation in the extended public sector in Greece. Empl Relat 30(1):63-85

31. Marlow L, Inman D, Bentancourt-Smith M (1996) Teacher job satisfaction (ED 393; 802)

32. Martin AJ (2003) The student motivation scale: further testing of an instrument that measures school students motivation. Aust J Educ 47(1):88-106

33. Maslow AH (1943) A theory of human motivation. Psychol Rev 50:370396. https://doi.org/10.1037/h0054346

34. Maslow AH (1954) Motivation and personality. Harper \& Row

35. Mifflin (1995) Management and organization. South-Western Publishing Co
36. Milda A, Raimundas V, Aidas P (2011) Job satisfaction survey: a confirmatory factor analysis based on secondary school teachers' sample. Int J Bus Manag 6(5):41-50

37. Milliman JZ (1994) Companies evaluate employees from all perspectives. Pers J 73(11):99-103

38. Motowildo SJ, Borman WC, Schmit MJ (1997) A theory of individual differences in task and contextual performance. Hum Perform 10(2):71-83

39. Ofoegbu FI (2004) Teacher motivation as an essential factor for classroom effectiveness and school improvement. Coll Stud J 3(1):54-61

40. Pallant J (2011) SPSS survival manual. Allen \& Unwin, Australia

41. Peng Z, Lian Y, Forson JA (2020) Peer effects in R\&D investment policy: Evidence from China. Int J Finance Econ. https://doi.org/10.1002/ijfe.2028

42. Photanan T (2004) Human resource focus. Innographics Ltd

43. Rao TV (2004) Performance management and appraisal systems: HR tools for global competitiveness. Sage Publications Inc

44. Rasheed MI, Humayon AA, Awan U, Din Ahmed A (2016) Factors affecting teachers' motivation. Norwich 30(1):101-114. https://doi.org/10.1108/ JJEM-04-2014-0057

45. Rasheed MI, Sarwar S, Aslam HD (2010) Motivational issues for teachers in higher education: a critical case of IUB. J Manag Res 2(2):1-23

46. Reizer A, Brender-llan Y, Sheaffer Z (2019) Employee motivation, emotions and performance: a longitudinal diary study. J Manag Pschol 34(6):415-428

47. Ricks BR, Glinn ML, Daughtrey AS (1995) Contemporary supervision, managing people and technology. McGraw-Hill Inc, New York

48. Rigby CS, Ryan RM (2018) Self-determination theory in human resource development: new directions and practical considerations. Adv Dev Hum Resour 20(2):133-147

49. Robins SP, Coulter M (2005) Management, 7th edn. A Pearson Education Company

50. Rosser VJ (2005) Measuring the change in faculty perceptions over time: An examination of their work life and satisfaction. Res High Educ 46(1):81-107. https://doi.org/10.1007/s11162-004-6290-y

51. Sharma RD, Jyoti J (2009) Job satisfaction of university teachers: an empirical study. J Serv Res 9(2)

52. Spector PE (1997) Job satisfaction: application, assessment, causes, and consequences. Sage Publications Ltd

53. Stafyarakis M (2002) HRD and performance management. University of Manchester

54. Stevens J (1996) Applied multivariate statistics for the social sciences. Lawrence Erlbaum

55. Tabachnick BG, Fidel S (2013) Using multivariate statistics. New Jersey Education Inc

56. Tillman WR, Tillman CJ (2008) And you thought it was the apple: a study of job satisfaction among teachers. Acad Educ Leadersh J 12(3):1-18

57. Trépanier SG, Forest J, Fernet C, Austin S (2015) On the psychological and motivational processes linking job characteristics to employee functioning: insights from self-determination theory. Work Stress 29(3):286-305

58. Viswesvaran C, Ones DS (2000) Perspectives on models of job performance. Int J Sel Assess 8(4):216-226

59. Weisburd D, Britt C (2013) Statistics in criminal justice, 4th edn. Springer, Berlin

60. Yamane T (1967) Statistics, an introductory analysis, 2nd edn. New York Harper and Row, New York

\section{Publisher's Note}

Springer Nature remains neutral with regard to jurisdictional claims in published maps and institutional affiliations. 